$1(32) / 2016$

\author{
Martins Veide \\ University of Latvia, Latvia \\ martinsw@inbox.lv
}

\title{
The philosophical view of learning from existential experiences in childhood
}

\begin{abstract}
Summary
This article analyzes the topicality and the understanding of an existential question in the context of life-learning in childhood. Discussing the topicality of the theme of death in childhood, the article provides an answer to the question - what does a child learn from his existential experience when facing death, and what is the significance of this experience in his further development? The existential experience of the child affects such developmental aspects of his personality as the overcoming of his helplessness and anxiety management, intellectual development, responsibility, and renunciation of hostility and destructiveness. As the experience of a child is formed in conjunction with the adult world and its inherent existential anxiety, it is important for a teacher to come to terms with himself, without relying on systems and ideologies.
\end{abstract}

Keywords: learning, children, experience, existential, death, responsibility, awareness

\section{Introduction}

In the information society a common form of existence is to have, which in the education process implies obtaining more and more information. This is promoted by rapid technological development. And thanks to the media as an important children's socialisation resource, children are often more informed and technologically more proficient than adults. However, the speed and wealth of information does not allow one to stop and reflect. One's own experience is not apprehended, and information in itself does not turn into knowledge.

According to the German philosopher Martin Heidegger, the recent cultural development process is characterised by complete oblivion as to the essence of existence and the authority of the impersonal subject (Heidegger 1967). Already starting from childhood, people are learning by saying what has already been said by someone else, and not trying to understand what is happening. Things are the way they are because people say they are that way. Furthermore, this is not limited only to the spoken word speaking, but also to written literature. In everyday life we can observe how people who are trying to obtain as much information as possible (thinking that this is knowledge) are subject to mass communication media and their "universal truth" - how to behave properly, how to dress properly, how to think properly, etc. Despite the fact that this "universal truth" alienates 
a person from himself, from his awareness of his own existence, in the light of classical philosophical enlightenment efforts, this is still being practiced at schools as knowledgelearning. According to the author of the definition of the learning process dimensions, Michael Göhlich, knowledge-learning focuses on know-what (Göhlich, Zifras 2007). Traditionally, knowledge-learning is closely linked to the main task of the official educational institutions. Apparently this is because, unlike the other aspects of learning, knowledge is perceived as something that can be separated from the individual. This enables the school to teach knowledge as an object and measure learning results, which can be assessed according to standard criteria, not related to the context. In other words, by replacing the personal experience with the impersonal, which is characterised for everyone, the acquired studies in the educational system become more easily definable and assessable. Evaluation becomes primary. At schools children primarily do not try to understand the subject themselves, and their lives, but rather try to learn to earn good grades, and assess themselves and others. In the new form of existence, according to M. Heidegger, the individual is concerned with how things are (Heidegger 1967). The person is focused not on the existence of things but on their characteristics, and their evaluation.

The modern human being, who is taken over by his own existential sense of finality, has to constantly plan his time and do his best to ensure a better, more valuable use of it. The assessments of the potential benefits of time management start in early childhood: "I would like to go out in the yard and play with other children in the sandbox... but, if I obey my Mum and stay at home and do not make my new dress dirty, she will allow me to go with her to the store". Along with starting the first days at primary school, the use of time continues to develop: "I would like to watch some cartoons, but if I instead finish my homework, I will get some new computer games." The growing individual, who tries to become part of the existing culture, eventually faces time pressure and, living in an endless rush and anxiety, is no longer aware of why and where he is rushing. The question of how to curb the dictates of time and at the same time not waste one's life on unimportant minutiae is related to the art of living or, as described by M. Göhlich, the learning dimension of livinglearning (Göhlich, Zifras 2007). Nowadays, this learning dimension is not only related to the increase of awareness and the restructuring of one's perception, attitude and action, but also the originality of an individual, one's realisation of own distinctiveness.

From ancient times, the learning process of the art of living has emphasised the actively receptive and philosophically reflective contemplation of one's own mortality. Despite the mass information available and its continuous increase, death for a modern day individual remains a great enigma. Death remains a problem that cannot be resolved in the usual way - with the help of science and mechanical technologies. And this problem appears to be important, not because every life ends with death, but because it creates a lot of anxiety for many people, which deprives them of satisfaction with their own life. This anxiety - especially in childhood - is often unintentional and, as shown by the observations of the therapists, is often explained with other, inadequate reasons (Yalom 2008: 16). Although one of the main tasks of development is the management of one's helplessness 
and fear, child developmental researchers still pay too little attention to it. But since death as an integral part of life refers to living-learning, the child learns about it regardless of whether this topic is included in the study programmes of the official educational institutions or not. The question that remains is - what does the child learn about it?

The author proposes the task of analysing the importance and understanding of the existential nature questions in childhood in the context of life-learning.

The research question is: What do children learn from their existential experience in the face of death, and what is the significance of this experience in their further development?

Research method: analysis of scientific literature and sources.

\section{Adults' attitude towards the child's existential questions}

Most children are curious. They want to know everything about their own lives. But an adult who has long stopped questioning himself, who "knows everything", not only cannot satisfy the child's curiosity, but is also afraid of it. Hence, the adult is either trying not to notice the child's existential questions or to draw his attention to a well-paid job, marriage, heritage, natural sciences, or religion...

At the beginning of the last century, the deathbed was not hidden from a child, but he was deprived of information about sex. At the beginning of our century one can observe the opposite picture. The parent, who a moment ago without any difficulty had explained in detail to his child about his birth and the process of how children are created, out of a sudden gets confused and starts to use vague and inconclusive answers, once the child asks him about death. A child may not understand, but he feels very well his parents' emotions - anxiety and confusion - once he has asked about death. The child perceives the precarious emotional atmosphere even if externally his parent tries to calm his child and draw his attention to other topics. It is worth noting that the child's question about death is always so "unexpected" and confusing, because adults themselves have a very vague notion about this theme. But the question "where to?" during all life is not less important than the questions "where from?"

Psychologist Herman Feifel describes two different views on death: death as a door and death as a wall (Feifel 1977: 5). During times, when the religious view of life was dominant, death was seen as a door to a better, more complete existence that will continue in a wonderful other-world, which the mortal cannot even comprehend. In the modern world where belief in a life after death is dimming, more and more people perceive death as a wall at which the journey of life ceases. Even for those people for whom regular church attendance is an integral part of their lives, physical decomposition of their body is usually the most fearful theme to contemplate or talk about.

In a split second death shamelessly violates several modern European Human Rights Conventions - it destroys the human rights to life, private and family life, fair trial, freedom of expression... Apparently that is the reason why death is being treated accordingly - with ignorance, rejection, and hatred. 
The "polite" part of society has expelled death from social discourse. The theme of death is being avoided, especially in any interaction with children. People talk about it quietly, so that children cannot hear about it... If, however, it is not possible to escape from this topic, then one talks about it with euphemisms. When answering a question "where from?" a modern adult finds it foolish to tell his children that "the stork brings babies" or that "babies are found in sauerkraut". Nevertheless, when answering a question "where to", the adult explains that "the grandmother has gone on a long, far journey" or that "the grandfather is now resting in a beautiful garden". Mentioning death seems for the adult strange and vulgar. As noted by the English anthropologist Geoffrey Gorer half a century ago, death has become the new pornography (Gorer 1955: 49). If pornography is naturalistically depicted copulation without loving feelings, then, by analogy, death which is detached from all natural, despite being a very sad experience, is also pornographic.

Despite the research and publications in the social and behavioural sciences during the last century, most European citizens today continue to ignore the inevitability of death and its probability at any moment (despite the statistically calculated greater probability of dying at an old age). The struggle with the fear of death takes place without trying to see it or hear about it. In contrast with our ancestors, who killed their meal themselves, a modern human being, even when disparagingly referring to vegetarianism, rarely thinks about the process that took place before his food became a nice package on a store shelf. Also the process of a dying person moves from home to hidden corners of our society - hospitals and specialised medical institutions. Professionals deliver the dead body to the morgue without the public seeing it. Before the funeral ceremony the corpse is dressed and put in order to make it look like a "living person". Then the corpse is put in a suitable coffin with a mattress and headrest, so that it would feel as comfortable as possible... This does not take place at home where rooms are called "living rooms", but instead at special funeral premises. Also, the terminology of the funeral industry shows sensitivity towards the human abomination of death - people are not dying, they simply "pass on". The funeral office employee becomes a consultant, but the cemetery - a memorial. Death seemingly disappears from our society. Seemingly, but not in reality.

Since death has become "invisible" and in our daily lives we do not experience real death, we "intoxicate" ourselves with bloodcurdling death characters as shown in the mass media. We comfort ourselves with the fact that this all is not real... Death in movies, computer games and news (also as a shock) becomes a commodity that entertains and distracts attention from horrifying emotions. The mass media make it possible to be present, to see the "real" death, but at the same time not to experience the emotions that accompany it in real life. Hence one can conclude that since the article written by G. Gorer in the middle of the last century the pornographic death phenomenon in our culture has only grown and further strengthened.

In turn, the child's perception of life is affected by the environment in which it grows up. Educational psychologist Lev Vygotsky demonstrated cultural and social internalisation in the concepts of a child's life (Vygotsky 1978). The world of adults, which the child is facing, plays an important role in the development of a child's existential notions. 


\section{The topicality of the death theme in childhood}

Frequently the topicality of existential questions is attributed to people at middle age when a person has breached the mid-point reference line of average statistical life expectancy, has gained some experience and has begun to realise that all ideas born in youth might not be realised after all. Furthermore, the contemplation of one's own existence is accompanied by a philosophical atmosphere, for which a child is not yet so to speak, ready. Still, the absence of abstract thinking and lack of understanding of the concepts "alive" and "dead" do not obstruct the child from building a relationship with death - to think and be curious about it, to be afraid of it, to create a magical protection from it and later on throughout the whole life to remember the death-related experience. Child psychoanalysis pioneer Melanie Klein has concluded that children experience a close relationship with death much earlier than acquiring intellectual knowledge about death. The fear of death is one of the earlier life experiences and these are the primary source of anxiety (Klein 1948: 114).

The willingness of parents and teachers to conceal certain themes (sex in the past, and now - death) can be attributable to a desire to maintain the child's purity, so that he will feel happy for longer. And this motive - to protect children - is a very natural one. Nevertheless, the ignoring of the theme of death by parents and teachers does not promote its disregard by children. As is the case with the theme of sex, children find other sources of information - often much more frightening and more absurd than the reality. Insufficient knowledge on how humans die makes them experience strong fear. Despite the imperfect knowledge of death, children often perceive it as something terrible and frightening - for children, death means to be abandoned and thrown away, to be trapped switched in a box deep under the ground, to slow rotting in a cemetery, to experiencing a lot of pain and suffering, etc. Therefore, the fear of death has a largely neurotic nature.

It is doubtful whether in this case the saying "the less you know, the better sleep you will have" justifies itself. Clinical specialists acknowledge that the fear of death is an important factor for insomnia not only in children but also in adults. Developmental psychologist Erik Erikson begins his book "Childhood and Society" with an example in which the idea of death as a mental stimulus becomes a cause of epileptic seizures for a four year old bоy (Эриксон 1996: 14). It is important to note that in this particular example the fact that his grandmother had died was initially carefully hidden. The boy manages to recover when the specialist discovers the guilt that he has had in connection with the "disappearance" of his grandmother (the boy has been disobedient) and the related fear of being punished with death - to be locked in a long box.

Psychiatrist Irvin Yalom indicates a close link between the death-related anxiety (although hidden) for parents and the inclination towards such psychological orientations as schizophrenia for their children (Yalom 1980: 105-107). In contrast to a typical European's idea about the "wildness" of cannibalism, I. Yalom compares the experience of a child from a Western culture, who experiences unclear anxiety when feeling the fear of the adult about life, with the experience of a child from the Fore culture (Papua New Guinea), who 
participates in the process of eating his deceased relative. The latter is not as catastrophic, as it takes place in the presence of an adult who does not feel any anxiety and perceives death as a natural component of the flow of life. Anthropologist Margaret Mead made observations in Samoa, another Oceanian Island, and concluded that sex, birth, and death in this culture are not hidden - children from birth see these processes in the presence of an understanding adult; hence, they do not have such psychological trauma as the continental people sometimes experience for the remainder of their lives (Mead 1952: 138).

The personal fear and denial of death of adults (parents, teachers, and child development researchers) distort their vision of children's existential experiences. Parents often do not realise how important for children are their questions about death. Psychiatrists' R. Lapouse's and M.A. Monk's study about the fears of 6 to 12-year-old children shows that every second mother evaluates the death-related concerns of her child lower than the child himself (Lapouse, Monk 1959: 803).

Psychoanalyst Gregory Rochlin claims that anyone who is willing to listen to children and observe them playing can obtain a lot of confirmation that a child, much earlier than is commonly thought, learns about death and the fact that it will happen to himself and to the people that take care of him (Rochlin 1965: 67). This conclusion is derived based on game sessions with children aged 3 to 5 years. It is difficult to identify the fear of death with the same confidence for children under 3 years of age due to the limited options of verbal communication. However, the founder of the organisation "End Violence against the Next Generation", school psychologist Adah Maurer relies on the assumption that even an infant during a panic attack in the middle of the night, when lying in a dark room without any external visual and auditory stimuli, is experiencing fear of non-existence (Maurer 1966: 35). Psychiatrist Max Stern has drawn a similar conclusion when studying nocturnal panic attacks - that children are afraid of "the complete nothing" (Stern 1951: 302).

One of the first child's verbal statements is: "all gone". Children refer this to, for example, a flame when a candle is blown out or water in the bath when the plug is pulled out. Here it is important to note the animistic thinking that is characteristic for children. Already at the end of the $19^{\text {th }}$ century, English psychologist James Sully wrote that any apparently self-generated or spontaneous movements, for small children mean a sign of life (Sully 1896: 96). Thus, for example, a flame of fire, running water, a falling leaf, and even a kettle with a hopping lid on the stove are perceived by children as living creatures. For a child, the interruption of the presence of a flame is like an end for a living creature. Furthermore, the poetic language used by adults - "the fire flame is dancing", "the moon is looking inside the window", "the river is travelling to the sea" - only further confirm such notions.

Among other things, "all gone" is also applicable to the faeces in the toilet bowl when water is being flushed. It is hard to find a child who would not be frightened to be engulfed and flushed away in the drain. Nowadays fear is further reinforced in the advertisements of toilet care products which expressively depict the horrifying creatures living in the toilet bowl. According to the observations of the author of this article, this type of fear 
can prevent a child from using the toilet bowl even at the age of $6 \ldots$ In the psychological literature "the battles with toilet bowl" at the age of 2-3 years are mainly associated with anal eroticism and the confirmation of abilities. However, another important factor here might prove to be the fear about one's extinction, loss of physical existence.

It is interesting to note that in existential philosophy, which postulates that existence precedes essence, a human being with his consciousness is "nothing", because he never was who he is and because he is constantly dynamically becoming (Sartre 1960: 60-65). This does not mean that the human being does not exist. This points to a person's freedom to choose their own essence. And this, in turns, suggests the idea that the fear of nonexistence actually means the fear of one's own freedom.

\section{Existential aspects in the context of a child's learning}

The topicality of existential aspects in the context of children's development is not only related to the fact that overcoming the helplessness and fear management of own disappearance is one of the main tasks of their personality development. It plays a role also in a child's intellectual development.

Permanence is an important concept, because it is important for one's own self-sufficiency. On the one hand a child cannot notice the disappearance (termination) of the object before he has realised its permanence. But on the other hand, there is no sense of permanence without the perception of change, loss, or termination. Thus, the concepts of permanence and change can only develop together. Oscillation between permanence (being, essence, existence) and disappearance (non-being, non-existence, death) plays an important role in the child development (Yalom 1980: 90).

Jean Piaget, the founder of the cognitive development theory, stated that death is an important subject in the development of understanding causality for children (Piaget 2005: 106). Typical for the thinking of early childhood is the link between cause and motive, where the existence of things is explained with motivation. As the death of an animal or a human being usually cannot be explained with their desire to die, then along the awareness of the death the child's thinking starts to change - he gradually begins to realise that the cause of death can also be the law of nature.

From the history of art and literature we are well aware of numerous examples of the reverse process when death is personified (e.g., as in the painting by the Latvian painter J. Rozentals). Obviously, this is not related to cognitive efforts to understand reality, but a way to relieve anxiety. A person has will. So the death of the person can also be reluctant to take someone with her; one can try to persuade it... It is simply necessary to find the right option. Such understanding draws the attention from the awareness of existence to the search for a proper existence. And it strengthens the dualistic thinking - if something can be done properly, then automatically an improper act is possible as well. If there is a right way of living, then there is also a wrong way of living. In this way life turns into a fight - the fight for right and against wrong. The child initially does not evaluate his ac- 
tions. With sincere passion and interest the child throws down toys, smears his breakfast porridge on the table, examines his excrements in the toilet bowl and is not concerned, whether any of these actions are right or wrong. Then the child is taught what is right and what is wrong, so that he will become manageable. The child becomes obedient thanks to the instilled guilt about the wrong-doing and the fear of punishment. Thus, moving away from the reality and from the non-duality, the associated anxiety, paradoxically, serves for the child's upbringing.

During childhood a human being in his permanent cognitive activities inevitably faces the real facts of life, including death and its related anxiety. Later it learns and, is taught to deny reality. In fact, already at the moment when the child feels the anxiety of his parents (parents suffer seeing that their child has "bonded" with the idea of death), it begins to learn to suppress its feelings. The child concludes that his parents will not be able to help him anyway.

When integrating in the cultural environment, the existence of death for the child gradually more and more moves into the unconsciousness. Nevertheless, the death-related anxiety does not decrease as a result of that. According to I. Yalom, it just becomes latent (Yalom 1980: 91). The introspective tendencies and the aspiration towards verity, which are characteristic of adolescence, once again induce the human being to face the inevitability of death and look for new ways to cope with the facts of life and the revived anxiety. What has the human being at this age group learnt about dying and death? The "knowledge" of an adolescent can be observed in his slang: "Deadly cool!", "Deadly long...", "Deadly boring...", "Almost died from laughter!", "Dead ball...", etc. These carefree imaginative expressions death represents the "extreme", the "non-visible", and the "inactive".

In order for them to acquire certain skills and knowledge that will help them in the future to earn their living, parents send their children to school. In fact, the child is put into a system, a system, which has its ultimate goal - a child who grows into a competitive professional. At school the child indeed acquires knowledge in various subjects - literature, mathematics, science, language skills, etc., which later helps him in the competition. But hardly the same could be noted with regard to the knowledge that he gains about himself and about life. Important questions about his existence largely remain unanswered. During life science classes the pupil learns that his body's life is an oxidation process, in other words combustion. In fact, he learns that his existence is similar to existence of a candle. In order to understand oneself, M. Heidegger invites everyone to rethink the meaning of one's existence, and not only obtain the naturalistic details (Haidegers 1991: 21).

Of all the possible knowledge that can be obtained during the learning process, each individual always has some that he can apply in his future life and a part that is not being used. Death is not something that can happen. It is something that will definitely happen. Knowledge, for example, about what is reality, what is consciousness, what happens after bodily death, clearly belongs to the first part. These questions as important scientific issues were mentioned in the magazine "New Scientist" on their $50^{\text {th }}$ anniversary (The biggest questions ever asked 2006). Nevertheless, this life dimension is not being taught at schools 
as part of the globally regulated training programmes. Instead, any reminder of the existence of death is seen as something morbid, as resentment for the unreal world of illusions, in which the human being lives nowadays. And the meaning of life is simplified with the completion of professional duties. Is it not because governments are more interested in fearful, qualified specialists rather than harmonious personalities who do not feel the anxiety and, hence, are less manageable? Personality as a process that is never finished, is not clearly definable or structural, it does not fit into a system. Philosopher Jiddu Krishnamurti in his book "Education and the Significance of Life" indicates that there is a distinction between a personality and the personal (Кришнамурти 2003: 7-8). The education system is not based on the personality, but on the personal. It teaches one to strive for personal safety and benefit, teaches one to fight for one's "place in the sun", while at the same time nurturing anxiety about oneself. The education system requires the child to follow the common way and thus does not allow him to experience himself as a process unified with the surrounding world.

Over the past hundred years, thanks to medical advances and the increasingly available preventive services, there has been a significant drop in the number of natural deaths for children. However, the same cannot be said about the number of violent deaths in the same period. Despite the sad historical experience, still nowadays on our Earth there are new wars, and more and more social conflicts based on the evaluations of external differences. Obviously there is one message that is not inconsistent with our education system and which we learn quite early and thoroughly: in order not to get destroyed, we need to destroy others...

Latvian mass media regularly report on the bursts of violence among pupils. Parents blame the teachers. School teachers pinpoint weaknesses in the upbringing of children in their families. However, neither of them see the communality of the abuse problems of children and adolescents, which is the existential aspect.

When a child finds that the return of an extinct object (e.g., a discarded toy from the child bed, flowers in spring, the newly lit flame of a candle, etc.) is not a universal law of nature, he tries to find new ways to protect himself from extinction. This is achieved by "taking over control into one's own hands", e.g., the defence mechanism called identification, which Anna Freud described three years after the burning of her father's books (Freud 1936: 125). The essence of identification includes the avoidance of threats, interjecting the threats bearing image in one's own psyche. Namely, from the threatened one the child turns himself into the one who threatens. If initially the child is watching with concern the disappearance of the moving (hence, living) things, then later he himself with a great pleasure blows out a candle, pulls out the plug in the bath, flushes the toilet, etc. If he, for example, has a fear of ghosts, he with a great pleasure will dress himself as a ghost to scare other children. Analogously, in order to protect himself from the fear of extinction, the child himself becomes the "carrier of death" - either symbolically, for example, by playing with toy soldiers who are "at war" and "kill" one another, or in a more literal sense, for example, by killing an insect or a reptile. Psychological defence mechanisms do 
not solve problems, but only deepen them and delay addressing these. And the stronger the latent anxiety related to a possible disappearance, the more destructive is the external form of the child and adolescent identification. As noted by the psychoanalyst Karen Horney, a child's hostility and destructiveness are directly proportional to his sense of a threat to his survival (Horney 2013: 9).

The same adults, who are so much concerned that their child should not face a real natural death and are puzzled by their child's manifestation of hostility and violence, do not notice how they themselves are keen on violent death. Detective stories, thrillers, westerns, and horror movies are such massively consumed products in the modern adults' world! And those same adults will most likely not admit that the thing that so entertains the, by its nature, is something very similar to pornography - naturalistically vulgar, obscene representation of (though this time not sexual intercourse), but death in a literary or artistic work. Censorship is never effective. The forbidden theme attracts and creates abnormal curiosity about it. This also applies to the theme of death. The pupil of A. Freud, Erna Furman, worked for a long time as a teacher with children who had lost their parents. She observed that specific information about death to some extent was helpful for them, but when adults deliberately or unconsciously distorted or blurred the facts, the child's situation only became more complicated (Furman 1981: 5). It is worth noting that an open recognition of the fact of human mortality does not only create anxiety and sadness, but also unites, blurs the boundaries between the living beings. It can be said that the existential nature of the reality of life makes us all brothers and sisters.

The fundamental question about death in the context of learning actually is - what exactly does a child learn or what can he learn? Does the child during his life gradually become aware of death or does he know everything straight away and gradually learn to cope with it, and accept it? Generally, it is assumed that knowledge of death appears as an empirical fact from the observation of another person's or an animal's death. However, a second option is also possible. Philosopher Max Scheler believed that the essence of death is something quite different from empirical and inductive knowledge, and that each of us has an intuitive knowledge about it (Max Scheler 1974: 68). This means that a child does not even need external experience, for example, the funeral of a relative or a visit to a fish shop with one's parents, to understand that there is death. But the scientific view of the world (on the body as a set of physical-chemical processes) for a modern intellectual does not allow him to openly accept such intuitive knowledge of death as an integral part of his life. Death is increasingly perceived as something external and destructive. In addition, according to M. Scheler, death is something that always happens to others. It is also interesting, that as is the case with oneself, death is expected as an event of another for the other living people. This is consistent with the findings of M. Heideger, who notes the characteristic trait of a modern human being, namely, forgetting one's own existence - a person as if dissolves in "others". Besides, these "others" are uncertain others - they are not a particular part of or a whole society, but the mediocre ordinary ("das Neutrum", often marked with an indefinite pronoun "man") (Heidegger 1967: 126). 
Distraction from self to others is also associated with responsibility. Virtually any religion makes rules, which, if followed, can help one to avoid death. Such rules not only provide comfort to the anxiety of extinction, but also give authority - religion, as it were, takes responsibility for the individual. It "rescues" the human being from the frightening confrontation with his personal freedom. But that does not mean that the transfer of responsibility for one's life is possible only in more religious schools. Atheism denies the existence of God, but not the notion that essence - once and for all time given, ready-made human nature - is before existence. If so, then the scientist as the predicate of the mystery of the universe becomes entitled to think on behalf of other society members and enlighten them. Since the beginning of the Neoteric culture such spiritual custody trends affect virtually all areas, but especially - pedagogy.

An adult, when participating in the child's development with the noblest purposes, makes up the child's personality, according to his perceptions of the expected improvements. In fact, such a parent or teacher is driven by an interest in what the child should become, and not by an interest in what the child, with his difficult to understand personality, already is. The child as he should be becomes more important than the child as he already is. The ideal becomes more important than the child's own existence. At the same time, failure to comply with the desired ideal first creates internal dissatisfaction, and then puts the blame on the "outside world" - "bad teachers", "careless parents", "wrong education system", "ill-bred children"...

In a social environment with a dominant notion of a one man's responsibility for other people, it is almost impossible to expect the development of taking responsibility from children. Children cannot stand freedom - they demand limits and structures. Research by Latvian teachers has shown that students want supportive and caring teachers, they want to have a creative learning environment in their classes and to have their interests safeguarded, but at the same time they do not want to take responsibility for their actions and learning curricula (Daniela, Kalniņa 2008: 404). But we would like children to be independent, responsible...

If there are no rules and no predetermined values or ideals to strive for, then nothing in this world has any other meaning than the one that the individual has granted himself. Then all one's life, all that one has, is created by oneself and no-one else can take responsibility for it. The only thing that remains is to be aware of it. It is hard to believe that one could find any selfish purpose or personal interest of the teacher if during the learning process he is trying to help the children to realise themselves. Nevertheless, such inherent design of one's essence and the realisation of one's responsibility is really frightening. This realisation is subjectively experienced as emptiness or as groundlessness. Selfresponsibility is related to the existential loneliness as a separation, not only from other people, but also from the world - the way we usually perceive it. Many existentialists note this anxiety of groundlessness as an even deeper one than the death-related anxiety. That is the reason why since childhood we are looking for something bigger, grander than ourselves - some structure, authority. And the education system provides it. Information 
storage and systematisation, which is often referred to as education, offers the child a refined form of escaping from himself.

\section{Conclusions}

Adults often do not realise the topicality of the existential questions for their children, because they do not realise their topicality for themselves. To hide the fact that they truly do not understand themselves, adults spend a lot of time searching for security and status, which has an impact also on life concepts for the children.

Faced with the increased sense of anxiety by adults related to the incomprehensible existential theme, the child learns to suppress his feelings. This creates conditions for a child's anxiety to become latent, which may take the form of hostility and destructiveness.

Parents and teachers, who are trying to "protect" children from their existential experience, retract him into life learning, which is away from the reality, from one's realisation of own existence. It should be reckoned that the child can learn to be freer, bolder, more responsible, without avoiding situations which make it possible to live a suitable, but often (also for an adult) horrifying existential experience.

Nowadays, the widespread oblivion of existence and its meaning has a possible alternative form of existence - the awareness of being. It means not only a realisation of the shortness of existence, but also a continuous awareness of one's own existence and taking responsibility for "who I am" and not transferring it to "others". In this form of existence a human being faces himself as a creative self-expression of his being. It assumes both its capabilities and limitations, without trying to convert the surrounding world into an object of its own activities. And in this acceptance one experiences human freedom. A teacher cannot change the education system. However, he is free to realise its potential and limitations. A teacher can realise that life cannot be subjected to a system, that it cannot be put under any frames, no matter how noble are the motives which such efforts have. In order to create a relationship with a child based on mutual understanding a teacher must first have a clear understanding himself, without relying on systems and ideologies.

\section{References}

Daniela L., Kalniņa D. (2008), Skolotāju darbība pusaudžu mācību disciplīnas veicināšanā (Teachers'activities facilitating teenagers' learning discipline). Teacher of the 21 st Century: Quality Education for Quality Teaching (ATEE), 2008.

Feifel H. (1977), New meanings of death. NY, McGraw-Hill.

Freud A. (1936), Das Ich und die Abwehrmechanismen. Wien, Internationaler Psychoanalitischer Verlag.

Furman E. (1981), A child's parent dies: studies in childhood bereavement. New Haven, CT, Yale University Press.

Gorer G. (1955), The pornography of death. "Encounter", October.

Göhlich M., Zirfas J. (2007), Lernen: Ein pädagogischer Grundbegriff. W. Kohlhammer Verlag. 
Haidegers M. (1991), Vēstule par humānismu (Letter on humanism). "Grāmata", 10.

Heidegger M. (1967), Sein und Zeit. Tübingen, Max Niemeyer Verlag.

Horney K. (2013), Neurosis and human growth: the struggle toward self-realization. London, Routledge.

Klein M. (1948), A contribution to the theory of anxiety and guilt. "International Journal of Psychoanalysis", Vol. 29.

Lapouse R., Monk M. (1959), Fears and worries in a representative sample of children. "American Journal of Orthopsychiatry", Vol. 29, Is. 4.

Maurer A. (1966), Maturation of concepts of death. "British Journal of Medical Psychology", 1966, Vol. 39, Is. 1.

Max Scheler (1874-1928): centennial essays (ed. by Frings M.S.) (1974). The Hague, Martinus Nijhoff.

Mead M. (1952), Coming of age in Samoa. NY, The New American Library.

Piaget J. (2005), The language and thought of the child. London, Routledge.

Rochlin G. (1965), Griefs and discontents: the focus of change. Boston, Little, Brown.

Sartre J.P. (1960), L'Etre et le néant. Paris.

Stern M. (1951), Pavor nocturnus. "International Journal of Psychoanalysis", Vol. 32.

Sully J. (1896), Studies of childhood. NY, D. Appleton and company.

The biggest questions ever asked. "New Scientist", 2006, 18 November, No. 2578.

Vygotsky L. (1978), Mind and society. Cambridge, MA, Harvard University Press.

Yalom I. (1980), Existential psychotherapy. N.Y., Basic Books.

Yalom I. (2008), Staring at the sun. San Francisco, Jossey-Bass.

Кришнамурти Д. (2003), Образование и смысл жизни. Москва, София.

Эриксон Э. (1996), Детство и общество. Университетская книга. 